\title{
Improving Ketosis-Prone Type 2 Diabetes Diagnosis in Africa
}

\section{Dagoberto Álvarez-Aldana MD MS}

Diabetes mellitus (DM) is a serious health problem with highand increasing-prevalence and incidence around the world. Africa, with a considerable communicable disease burden, is not exempt and is facing greater DM risk due to rapid demographic, sociocultural, economic and nutritional changes. According to the International Diabetes Federation, Africa will experience the largest jump in DM prevalence (143\%) of all regions over the next 25 years.[1,2]

As a member of the Cuban medical team working in Luanda, Angola, l've repeatedly seen male patients presenting with newonset diabetic ketoacidosis (DKA) without evident precipitating cause. Medical records show these patients are between 40 and 50 years old; during ambulatory follow-up, they sometimes maintain good metabolic control despite having discontinued insulin therapy due to dramatic decline in glycemia. These clinical findings suggest the presence of ketosis-prone type 2 diabetes (KPD). Unfortunately, this variant of type 2 diabetes is often not considered during diagnosis and can lead to misclassification and incorrect treatment protocols.

Acute and chronic
complications from
diabetes require
continual, long-term
medical care and have
significant economic
and social impact on
health systems, patients
and their families

Acute and chronic complications from diabetes require continual, long-term medical care and have significant economic and social impact on health systems, patients and their families. DKA is a complex metabolic disorder caused by insulin deficiency occurring in type 1 diabetes, although under certain circumstances it is currently being more frequently ascribed to type

2 DM. While DKA is on the decline in high-income countries, in Africa it is steadily increasing among type 2 diabetics, though data is still sorely limited.[3] There, this hyperglycemic emergency translates into high mortality $(26 \%-29 \%)$, where diagnostic delay and resource scarcity are commonplace.[4]

In the 1960s in Africa, KPD was reported as "temporary diabetes." Thirty years later, this syndrome was reported in a small cohort of young African Americans. The scientific literature has described this type of diabetes in a variety of ways: idiopathic type 1 diabetes, atypical diabetes, Flatbush diabetes and type 1.5 diabetes.[5] In 2019, WHO included it in its new classification of diseases, within the hybrid forms of diabetes.[6] In the United States, the estimated prevalence of KPD is between $20 \%$ and $50 \%$ of African Americans and Hispanics with newly-diagnosed diabetic ketoacidosis.[7]

Clinically, DKA typically presents as recently-diagnosed diabetes with short-lived, but acute, hyperglycemia symptoms. Most patients report less than four-week cycles of polyuria, polydipsia and weight loss. This is most frequently seen in middle-aged overweight and obese men who also exhibit other physical signs typical of DM including acanthosis nigricans and abdominal adiposity. In $80 \%$ of cases, there is a family history of diabetes, with an onset of acute hyperglycemia and ketosis or diabetic ketoacidosis. Autoimmune studies are negative in the majority of cases. Patients usually present with markedly high glucose levels ( $>500 \mathrm{mg} / \mathrm{dL}$ ), mean glycated hemoglobin (A1c) $>10 \%$ and a blood $\mathrm{pH}<7.30$, accompanied by ketoacidosis.[5]

Hypotheses regarding implicated physiopathological mechanisms focus on $\beta$ cell dysfunction. Although underlying factors are unknown, researchers posit that $\beta$ cells are more susceptible to deterioration when there are prolonged high levels of blood glucose (glucotoxicity) or free fatty acids (lipotoxicity). With ketoacidosis, the presence of reduced $\beta$-hydroxybutyrate oxidation, together with greater branched-chain amino acid catabolism, leads to ketogenesis.[5,7]

In my clinical experience with both hospitalized and ambulatory patients in Luanda, I've seen recently diagnosed diabetics presenting clinical factors similar to those described in the international literature that suggest KPD. Nevertheless, KPD is rarely considered as a diagnosis. This oversight has important clinical implications since it increases the risk of ketoacidosis. In my opinion, we need to conduct a comprehensive analysis of clinical findings-particularly in those populations where access to genetic, immunological and hormonal testing is extremely limited-to improve diagnosis and correctly classify diabetes. Analysis of this type would be especially helpful to health professionals working in resource-scarce settings in Africa and those without clinical experience with this type of diabetes.

\section{REFERENCES}

1. Saeedi P, Petersohn I, Salpea P, Malanda B, Karuranga S, Unwin N, et al. Global and regional diabetes prevalence estimates for 2019 and projections for 2030 and 2045: Results from the International Diabetes Federation Diabetes Atlas, 9th edition. Diabetes Res Clin Pract. 2019 Nov;157:107843. DOI: 10.1016/j.diabres.2019.107843. Epub 2019 Sep 10.

2. Atun R, Davies JI, Gale EAM, Bärnighausen T, Beran D, Pascal Kengne $A$, et al. Diabetes in sub-Saharan Africa: from clinical care to health policy. Lancet Diabetes Endocrinol Commission [Internet]. 2017 Jul [cited 2020 Nov 5];5(8):622-67. Available at: https://www.thelancet.com/journals/landia/article/ PIIS2213-8587(17)30181-X/fulltext

3. Murunga AN, Owira PMO. Diabetic ketoacidosis: an overlooked child killer in sub-Saharan Africa? Trop Med Int Health [Internet]. 2013 Nov [cited 2021 Jun 12];18(11):1357-64. Available at: https://onlinelibrary.wiley.com/doi/full/10 .1111/tmi.12195

4. Ndebele NFM, Naidoo M. The management of diabetic ketoacidosis at a rural regional hospital in KwaZulu-Natal. Afr J Prim Health Care Fam Med [Internet]. 2018 [cited 2019 Jun 11];10(1):1612. Available at: https://www.ncbi.nlm.nih .gov/pmc/articles/PMC5913763/

5. Vellanki P, Umpierrez GE. Diabetic ketoacidosis: a common debut of diabetes among African Americans with type 2 diabetes. Endocr Pract [Internet]. 2017 Aug [cited 2021 Jun 12];23(8):971-8. Available at: https://www.ncbi.nlm.nih .gov/pmc/articles/PMC6092188/

6. World Health Organizattion. Classification of diabetes mellitus [Internet]. Geneva: World Health Organization; 2019 [cited 2021 Jun 12]. 36 p. Available at: https://apps.who.int/iris/handle/10665/325182

7. Umpierrez GE, Smiley D, Kitabchi AE. Narrative review: ketosis-prone type 2 diabetes mellitus. Ann Intern Med [Internet]. 2006 Mar 7 [cited 2020 Nov 5];144(5):350-7. Available at: https://www.acpjournals.org/doi/ pdf/10.7326/0003-4819-144-5-200603070-00011

THE AUTHOR

Dagoberto Álvarez-Aldana (dagobertoalvar@gmail.com), physician with dual specialties in family medicine and endocrinology, Antonio Luaces 


\section{Viewpoint}

Iraola University Hospital, Ciego de Ávila, Cuba. Member of Cuba's international medical team in Luanda, Angola 2018-present.

https://orcid.org/0000-0003-1167-2323

Submitted: December 21, 2020

Approved for publication: June 16, 2021

Disclosures: None 